\title{
COMPARATIVE STUDY BETWEEN HOLMIUM: YAG LASER AND PNEUMATIC LITHOTRIPSY IN THE MANAGEMENT OF UPPER URETERIC STONE
}

\author{
MD. ASHIF CHOWDHURY ${ }^{1}$, MD. SHAHIDUL ISLAM ${ }^{2}$, SM SHAMEEM WAHEED ${ }^{3}$, MD. ABDUR RAKIB ${ }^{4}$, \\ FARUK HOSSAIN ${ }^{5}$, MD. HABIBUR RHAMAN ${ }^{6}$
}

\begin{abstract}
Background:Among various intracorporeal lithotripters, Pneumatic lithotriptorhas become the widely used tool for the treatment of ureteric stones. Recently the Holmium:YAG laser has been used with a wide range of potential urological applications, including intracorporeal lithotripsy of ureteric stones.
\end{abstract}

Objective: To compare the treatment of upper ureteric stone between laser and pneumatic lithotripsy.

Materials and methods: One hundred patients with upper ureteric stone who underwent ureteroscopic lithotripsy in the Department of Urology, CMH, Dhakafrom October 2012 to September 2015 were enrolled in this study. Patients were divided into two groups. Group $A(L L)$ were treated with holmium: YAG laser and Group $B(P L)$ were treated with pneumatic lithotripsy. Two procedures were compared in term of stone fragmentation, stone clearance rate, duration of lithotripsy, complications and duration of post operativehospital stay. Patients were monitored as outpatients after one month and after three months with a kidney ureter and bladder radiograph and ultrasonograph. Patients with migrated fragments or incomplete clearance underwent an auxiliary procedure such as Extra Corporeal shock wave lithotripsy (ESWL).

Results: Mean stone size was $1.36 \pm 0.36 \mathrm{~cm}$ in group $A(L L)$ and $1.37 \pm 0.36 \mathrm{~cm}$ in group $B(P L)$. The immediate stone clearance rate was significantly higher inGroup $A$ (94.0\%) than Group B (76.0\%). Fragments proximal migration were $6.0 \%$ in LL group and $24.0 \%$ in PL group. Use of stone retrieval equipments (baskets, forceps) was $16.0 \%$ and $64.0 \%$ in $L L$ and $P L$ group respectively $(p<0.05)$ and stone fragments clearance requiring auxiliary procedures were $6 \%$ and $24 \%(p<0.05)$ in LL and $P L$ group respectively. The mean lithotripsy time $40.46 \pm 19.25 \mathrm{~min}$ and $36.86 \pm 14.83 \mathrm{~min}$ and mean period of post operative hospital stay was $2.32 \pm 1.22$ days and $2.44 \pm 1.18$ days in the $L L$ and $P L$ group respectively. Periprocedural complications like hemorrhage, mucosal disruption/ perforation were almost same in both groups.

Conclusion: In this study stone clearance and fragmentation of stone in Holmium:YAG assisted ureteroscopy was significantly higher than pneumatic lithotripsy group. The need for auxiliary procedure like ESWL for proximally migrated fragments was significantly less inHolmium:YAG assisted ureterocopy compared with pneumatic lithotripsy.

Key wards: Pneumatic Lithotripsy (PL), Laser Lithotripsy (LL), Extra Corporeal Shock Wave Lithotripsy (ESWL)

Bangladesh J. Urol. 2019; 22(2): 160-165

1. Urologist, $\mathrm{CMH}$, Dhaka

2. HOD, Dept. of Urology, $\mathrm{CMH}$, Dhaka

3. Urologist, $\mathrm{CMH}$, Dhaka

4. Urologist, $\mathrm{CMH}$, Dhaka

5. Asst. Professor, Dept. of Urology, BSMMU

6. Professor of Urology, BSMMU, Dhaka

Correspondence: Lt Col (Dr.) Md. Ashif Chowdhury, Urologist, $\mathrm{CMH}$, Dhaka

Received: 05 February 2019

Accepted: 10 May 2019

\section{Introduction:}

Ureteral calculi may be associated with renal obstruction and care must be taken to prevent irreversible damage to the kidney. Patients with stone of $5 \mathrm{~mm}$ or less, conservative management may be considered. Whereas chance of spontaneous passage for larger stones and more proximal stones diminishes 


\section{2(2) 2019}

Comparative Study Between Holmium: Yag Laser and Pneumatic Lithotripsy in the Management of Upper Ureteric Stone

considerably and thus intervention is required. Treatment decision of upper ureteric stones is based on several general aspects such as stone size and symptoms. Currently most ureteral stones are removed by minimally invasive endourological procedure. Small stones may be extracted but stones of $>5 \mathrm{~mm}$ in diameter require intracorporeal fragmentation before removing the resultant fragments. The advancement of ureteroscopy and related working elements to manipulate or fragment uretral calculi has significantly increased treatment options for urologists. ${ }^{1}$ For stone fragmentation, a variety of lithotriptors can be used, including ultrasonic, electro hydraulic, pneumatic and laser lithotriptors. Pneumatic lithotripsy and Holmium:YAG lithotripsy have reported favorable outcomes. A rather simple principle of the jackhammer has enabled Pneumatic lithotripsy to be a safe and effective method for stone treatment[2,3]. Thus, the lithoclast has become a widespread tool for fragmentation of urinary stones. However, it has some disadvantages. Semirigid probe requires a rigid or at least a semi rigid ureteroscope and there is a high possibility of undesired retrograde displacement of the calculus[4,5]. The holmium:YAG laser has excellent stone fragmenting properties and as a result, it is now a well-established modality for intracorporeal lithotripsy[6]. Holmium laser light can be transmitted through a thin, flexible fiber compared with instruments for mechanical stone fragmentation. Holmium:YAG lithotripsy depends on photothermal mechanism for stone fragmentation, thus the risk of retrograde stone propulsion could be minimized, but it may cause thermal injury to the ureter if used carelessly. Endoscopic treatment of ureteral stones should be evaluated from the standard points of efficacy and the ultimate success rate of the various procedures.

The aim of this study is to evaluate and compare the outcome of the treatment of upper ureteric stone between laser and pneumatic lithotripsy.

\section{Methods:}

This hospital based comparative study was carried out in the Department of Urology, $\mathrm{CMH}$, Dhaka from October 2012 to September 2015. One hundred patients with upper ureteric stone who underwent ureteroscopic lithotripsy at above institution from October 2012 to September 2015 were included in this study. Patients were divided into two groups. In Group AHolmium:YAGlaser was used on 50patients and in group B pneumatic lithotripsy was performed on another 50 patients. Two procedures were compared in term of stone fragmentation, stone clearance rate, duration of lithotripsy, complications and duration of post-operative hospital stay. Patients were monitored as outpatients after one month and after three months with a kidney ureter and bladder radiograph and ultrasonograph. Patients with migrated fragments or incomplete clearance underwent an auxiliary procedure such as ESWL.

\section{Results:}

Table- I

Age distribution of the patients

\begin{tabular}{lccc}
\hline Age (years) & Group A & Group B & p value \\
\hline$=30$ & $9(18.0)$ & $13(26.0)$ & 0.521 \\
$31-40$ & $16(32.0)$ & $10(20.0)$ & \\
$41-50$ & $12(24.0)$ & $12(24.0)$ & \\
$>50$ & $13(26.0)$ & $15(30.0)$ & \\
Mean \pm SD & $41.90 \pm 10.97$ & $41.32 \pm 12.3$ & $0.804 n s$ \\
Min-max & $22-60$ & $20-60$ & \\
\hline
\end{tabular}

The mean age was $41.90 \pm 10.97$ years and $41.32 \pm 12.33$ years in group $A$ and group $B$ respectively.Only nine patient (18\%) in group-A and 13 patient $(26 \%)$ in group-B were below 30 years of age. There was no significant difference in age between two groups.

Table II

Gender distribution of the patients

\begin{tabular}{lccc}
\hline Gender & Group A & Group B & p value \\
\hline Male & $36(72.0)$ & $31(62.0)$ & 0.288 \\
Female & $14(28.0)$ & $19(38.0)$ & \\
\hline
\end{tabular}

Males were predominant in both groups. There was no significant difference in gender between two groups.

Table III

Side involved of the patients

\begin{tabular}{lccc}
\hline Side of involvement & Group A & Group B & p value \\
\hline Right & $20(40.0)$ & $22(44.0)$ & 0.685 \\
Left & $30(60.0)$ & $26(56.0)$ & \\
\hline
\end{tabular}

Involvement of the left side was more than right side. There was no significant difference in side of involvement between two groups. 
Table-IV

Size of the stones

\begin{tabular}{lccc}
\hline Size of the stones & Group A & Group B & p value \\
\hline $0.5-1.0$ & $15(30.0)$ & $15(30.0)$ & 1.000 \\
$1.1-1.5$ & $23(46.0)$ & $23(46.0)$ \\
$1.5-2.0$ & $12(24.0)$ & $12(24.0)$ \\
Mean \pm SD & $1.36 \pm 0.36$ & $1.37 \pm 0.360 .934 \mathrm{~ns}$ \\
Min - max & $0.80-2.00$ & $0.80-2.00$ \\
\hline
\end{tabular}

The mean stone size was $1.36 \pm 0.36 \mathrm{~cm}$ in Group- A and $1.37 \pm 0.36 \mathrm{~cm}$ in Group- B. The range of the stone size was $0.8 \mathrm{~cm}$ to $2 \mathrm{~cm}$ in both groups.

Table-V

Density of the stones

\begin{tabular}{lccc}
\hline Density of the stones & Group A & Group B & p value \\
\hline $525-575$ & $5(10.0)$ & $5(10.0)$ & 1.000 \\
$576-625$ & $7(14.0)$ & $7(14.0)$ & \\
$626-725$ & $21(42.0)$ & $22(44.0)$ \\
$726-775$ & $9(18.0)$ & $8(16.0)$ \\
$776-825$ & $4(8.0)$ & $4(8.0)$ \\
$>825$ & $4(8.0)$ & $4(8.0)$ \\
Mean \pm SD & $697 \pm 88$ & $695 \pm 890.943 n s$ \\
Min - max & $540-910$ & $530-900$ \\
\hline
\end{tabular}

The Mean density $(\mathrm{HU})$ of stone was $696.66 \pm 87.89$ in Group-A and 695.40 \pm 89.42 in Group- B. The density of large number of stones (21 in group-A and 22 in group-B) were in between $626 \mathrm{HU}$ to $725 \mathrm{HU}$. Only in 8 patients (four in each group) stone density were above $825 \mathrm{HU}$.

\section{Table-VI}

Time required for lithotripsy

\begin{tabular}{lccc}
\hline Time (minutes) & Group A & Group B & p value \\
\hline$=30$ & $24(48.0)$ & $18(36.0)$ & 0.173 \\
$31-60$ & $20(40.0)$ & $29(58.0)$ & \\
$>60$ & $06(12.0)$ & $03(6.0)$ & \\
Mean \pm SD & $697 \pm 88$ & $695 \pm 89$ & $0.297 \mathrm{~ns}$ \\
Min - max & $540-910$ & $530-900$ & \\
\hline
\end{tabular}

The Mean duration ( $\mathrm{min}$ ) of lithotripsy was $40.46 \pm 19.25$ in Group-A and $36.86 \pm 14.83$ in Group-B. In majority of the cases stone were broken within an hour in both groups. Only in $12.0 \%$ patient's lithotripsy time was more than 60 min in laser group and only in $6.0 \%$ patients lithotripsy time was more than $60 \mathrm{~min}$ in pneumatic lithotripsy group.

Table VII

The use of forceps/Dormia basket for stone retrieval

\begin{tabular}{lccc}
\hline Fragments retrieval & Group A & Group B & p value \\
\hline Yes & $8(16.0)$ & $32(64.0)$ & 0.0001 \\
No & $42(84.0)$ & $18(36.0)$ & \\
\hline
\end{tabular}

Forceps/Dormia baskets were required for retrieval of stone fragments in $8(16 \%)$ cases in Group-A and in $32(64 \%)$ cases in Group-B and in rest of the cases stone fragments were washed out spontaneously.

Table VIII

Stone clearance after Laser and Pneumatic of lithotripsy

\begin{tabular}{lccc}
\hline Outcome & Group A & Group B & p value \\
\hline Success & $47(94.0)$ & $38(76.0)$ & 0.0001 \\
Failure & $3(6.0)$ & $12(24.0)$ & \\
\hline
\end{tabular}

Complete stone clearance was significantly higher in Group A (94.0\%) than Group B (76.0\%).

TableIX

Peri procedural complications

\begin{tabular}{lccc}
\hline Complications & Group A & Group B & p value \\
\hline Nil & $42(84.0)$ & $25(50.0)$ & 0.002 \\
Hemorrhage & $1(2.0)$ & $8(16.0)$ & \\
Mucosal disruption/ & $4(8.0)$ & $5(10.0)$ & \\
perforation & & & \\
Stone migration & $3(6.0)$ & $12(24.0)$ & \\
\hline
\end{tabular}

Post operative haematuria occurred in $2 \%$ patientsin Group A and in $16.0 \%$ patients in group-B. Mucosal abrasion/ disruption was occurred in $8.0 \%$ patients in group-A and $10.0 \%$ patients in group-B. In $6.0 \%$ cases stone fragments were migrated proximally in group-A and in $24.0 \%$ cases stone fragments were migrated proximallyin group-B. Complication rate was significantly higher in PL group than LL group ( $p$ value 0.002). 
Table $\mathbf{X}$

Duration of post operative hospital stay

\begin{tabular}{lccc}
\hline Hospital stay (days) & Group A & Group B & p value \\
\hline$=2$ & $34(64.0)$ & $19(38.0)$ & 0.165 \\
$3-4$ & $11(22.0)$ & $29(58.0)$ & \\
$>4$ & $05(10.0)$ & $02(4.0)$ & \\
Mean \pm SD & $2.32 \pm 1.22$ & $2.44 \pm 1.18$ & $0.628 n s$ \\
Min - max & $1-6$ & $1-5$ & \\
\hline
\end{tabular}

The Mean duration (days) of hospital stay was2.32 \pm 1.22 in group A and 2.44 \pm 1.18 in Group B.

\section{Discussion:}

The goal of the surgical treatment of patients suffering from ure-teral calculi is to achieve complete stone clearance with minimal complication. A variety of lithotriptors can be used through an ureteroscope. Although there are some advantages and disadvantages, ${ }^{7}$ the Holmium laser and pneumatic lithotripters are most widely used in different centers for the management of upper ureteral stones[8].

The present study was designed to compare laser lithotripsy with pneumatic lithotripsy in treatment of upper ureteric stone.One hundred patients were included in this study. The patients were divided into 2 groups. In group-A (LL), 50 patients underwent laser lithotripsy andin group-B (PL), another 50 patients underwent pneumatic lithotripsy. Two procedures were compared in term of fragmentation time, stone free rate, size and proximal migration of the fragments, requirement of the use of forceps/baskets for stone retrieval and complications.

In this study, mean age of patients was $41.90 \pm 10.97$ years in LL group and $41.32 \pm 12.33$ years in PL group. There was no significant difference in the ages between two groups. This is general agreement with other reports in the literature[9,10].

In thepresent series, twenty right upper ureteric and thirty left upper ureteric stones were operated in group$A$ and twenty-two right upper ureteric and twenty-six left upper ureteric stones were operated in group-B.

In the present series, size of the stones ranges from $0.8 \mathrm{~cm}$ to $2 \mathrm{~cm}$. The mean size of stone was $1.36 \pm 0.36$ $\mathrm{cm}$ and $1.37 \pm 0.36 \mathrm{~cm}$ in group-A and group-B respectively.No significant difference in the size of stones was observed between the two groups. In the study of Sun et al. ${ }^{11}$, mean stone size was $11 \pm 2.5 \mathrm{~mm}$ in PL group and $12 \pm 2.3 \mathrm{~mm}$ in LL group.Mean stone size was $11.5 \mathrm{~mm}$ in LL group and $12.3 \mathrm{~mm}$ in PL group in the study of Bapatet al[12]. In other studies, mean size of stone ranges from 9 to $16 \mathrm{~mm}[6,9]$.

In this study, density of stones ranges from $530 \mathrm{HU}$ to $900 \mathrm{HU}$.The mean density of stones was $696.66 \pm 87.89$ $\mathrm{HU}$ in group-A and $695.40 \pm 89.42 \mathrm{HU}$ in group-B.No significant difference was found between the two groups.EAU guideline suggested that density of the stone is an important variable to decide the method of stone removal[13].

In our study, mean operation time was $40.46 \pm 19.25$ minutes and $36.86 \pm 14.83$ minutes in group-A and group-B respectively. No significant difference between the groups was found. In the study of Bapatet al. ${ }^{12}$ mean operation time was $38.85 \pm 8.99$ min for PL group and $45.61 \pm 11.30 \mathrm{~min}$ for the LL group. They also found no significant difference in operation time between two groups which was similar to our study. But Sun et al. ${ }^{11}$ in their study found significant difference in operation time in favour of laser lithotripsy. Operation time for laser lithotripsy was $49.8 \pm 26.4 \mathrm{~min}$ and $76.9 \pm 48.3 \mathrm{~min}$ in PL group.

Forceps/Dormia baskets were required for retrieval of stone fragments significantly lower in LL group (16.0\%) than PL group (64.0\%). Sun et al. ${ }^{11}$ reported that the stone should be fragmented into pieces $<3 \mathrm{~mm}$ to pass spontaneously.Jeon et al ${ }^{1}$, in their study found that the Hol:YAG laser virtually vaporizing the stone and the stone is fragmented into very small sizes, ranging from 1 to $2 \mathrm{~mm}$ which is also supported by another study by Vassar et al[14].Teichman et al[15]. showed that fragments of e" $4 \mathrm{~mm}$ are produced by all types of endoscopic lithotripters, with the exception of the Hol:YAG laser.In the present study fragments of stones were very small and which was confirmed by direct vision and fluoroscopy.

In this study, complete stone clearance was significantly higher in group-A (94.0\%) than in group-B (76.0\%). Whereasproximal migration of fragments was occurred significantly lower in Group-A $(6.0 \%)$ than Group-B (24.0\%).In one study, Maghsoudiet al[16]. revealed that stone fragmentation was $90.2 \%$ in LL group and $73.2 \%$ in $\mathrm{PL}$ group $(\mathrm{P}<0.05)$. They concluded that the overall stone free rate in Hol:YAG laser lithotripsy was better than pneumatic lithotripsy.Sun et al. ${ }^{11}$ reported stone free rate $95.7 \%$ in LL group and $69.7 \%$ in $\mathrm{PL}$ group.Bapat et al.[12] found complete clearance of stone in 166(86.1\%) patient out of 193 patients in PL group, whereas in LL group they noticed complete stone clearance in 195 (97.01\%) out of 201 patients. 
In this study, proximal migration of fragments was occurred in three $(6 \%)$ cases in group-A and twelve $(24 \%)$ cases in group-B.Proximal stone migration is the most disadvantage of the pneumatic lithotripsy and reported in the $2-17 \%$ of cases in the study of Fong et al. ${ }^{17}$ Jeon and associates ${ }^{1}$ reported that the main cause of failure in ureteroscopic lithotripsy was the proximally migrated stone/ fragments. They found upward migration of stone fragments occurred in $19.2 \%$ in the Pneumatic lithotripsy group while in $4.0 \%$ in the LL group.

Stone fragments migrated into the kidney with Pneumatic lithotripsy was $13.9 \%$ in one study by Bapatet al. ${ }^{12}$ whereas stone fragments migrated proximally in only $1.9 \%$ patients in laser group. Dasgupta ${ }^{15}$ also reported that the proximal migration of stone fragments is the main drawback to ballistic lithotripsy. Sun et al. ${ }^{11}$ found proximal migration of stone fragments in $19.1 \%$ cases in PL group. It was significantly higher than laser group.

Post-operativehaematuriawas occurred in one $(2.0 \%)$ patient in Group A and in 8 (16.0\%) patient in group-B. Mucosal abrasion/disruption was occurred in $4(8 \%)$ patients in group-A and $5(10 \%)$ patients in group-B. Uro sepsis was not occurred in either group probably due to use of antibiotics in peri operative period. In Bapat ${ }^{12}$ study, Ureteral perforation, which were mucosal, occurred in $2.9 \%$ patients in LL group and $4.6 \%$ patients sustained ureteral perforation in $\mathrm{PL}$ group. In one study Sun et al[11]. reported 5 ureteral perforation out of 141 patients. In another study, Monohoret al[18]. found no significant difference of mucosal perforation/disruption between laser and pneumatic lithotripsy.

In this study, hospital stay ranged from one day to 6 days with a mean of 2.32 days \pm 1.22 in the laser group and ranged from one to five days with a mean of 2.44 days \pm 1.18 in the lithoclast group. In one study, Sun et al[11]. reported that shorter post operative hospital stay was in LL group.In their study post operative hospital stay was 3.2 days in PL group and 2.5 days in LL group which was significant $(p<0.01)$. In another study, Jeonet al. ${ }^{1}$ reported longer post operative hospital stay in PL group than LL group.

\section{Conclusion:}

This study revealed that Hol:YAG laser lithotripsy is safe and more effective than pneumatic lithotripsy in respect of lower proximal migration rate of stone fragments, higher stone free rate and less requirement of forceps/baskets. The need for auxiliary procedure after Hol:YAG laser assisted URS is significantly less in comparison with pneumatic lithoclast.

\section{References:}

1. Jeon SS, Hyun JH, Lee KS. A comparison of holmium:YAG laserwith Lithoclast lithotripsy in ureteral calculi fragmentation. Int $\mathrm{J}$ Urol 2005; 12:544-547.

2. Denstedt JD, Eberwein PM, Singh RR, The Swiss Lithoclast: A new device for intracorporeal lithotripsy, J Urol, 1992;148:1088-90.

3. Denstedt JD, Razvi HA, Rowe E, Grignon DJ, Eberwein PM. Investigation of tissue effects of a new device for intracorporeal lithotripsy: the Swiss lithoclast. J Urol 1995; 153: 535-7.

4. Robert M, Bennani A, Guiter J, Averous M, Grasset D. Treatment of 150 ureteric calculi with the lithoclast. EurUrol 1994; 26:212-15.

5. Vorreuther R, Klotz T, Heidenreich A, Nayal W, Engelmann U. Pneumatic versus electrokinetic lithotripsy in treatment of ureteral stones. J Endourol1998; 12: \&233-6

6. Grasso M. Experience with the Holmium laser as an endoscopic lithotrite. Adult Urol 1996;48:199206.

7. Hofbauer J, Hobarth K, Marberger M. LithoClast: New and inexpensive mode of intracorporeal lithotripsy. J Endourol 1992;6:429-432

8. Erhard MJ, Bagley DH. Urologic applications of the holmium laser:Preliminary experience. J Endourol 1995;9:383-386.

9. Fong $\mathrm{Y}, \mathrm{Ho}$ Sh, Peh H, Ng F, Lim P, Quek P, et al . Extracorporeal shockwave lithotripsy and intracorporeal lithotripsy for proximal ureteric calculi. Ann Acad Med Singapore 2004;33:80-3.

10. Naqvi S, Khaliq M, Zafar M, Rizivi S. Treatment of ureteric stones, comparison of laser and pneumatic lithotripsy. BJU 1994;77:694-8.

11. Sun Y, Wang L, Liao G, Xu C, Gao X, Yang Q, Qian S. Pneumatic lithotripsy versus Laser Lithotripsy in the endoscopic Treatment of Ureteral Calculi. J Endourol 2001; 15: 587-590

12. Bapat SS, Pai KV, Purnapatre SS, Yadav PB, PadyeAS. Comparison of HImium and Pneumatic 
Lithotripsy in Managing Upper-Ureteral Stones. J Endourol 2007;21:1425-1427.

13. Turk C, Knoll T, Petric A, Sarica K, Straub M, Seitz C. Guidelines on urolithiasis. EAU guide line 2012 Feb: 934-1034

14. Vassar GJ, Chan KF, Teichman JM et al.Holmium:YAG lithotripsy: photothermal mechanism. J. Endourol. 1999; 13 : 181-90.

15. 15. Teichman JMH, Vassar GJ, Bishop JT, Bellman GC. Hol:YAG lithotripsy yields smaller fragments than lithoclast, pulsed dye laser or electrohydraulic lithotripsy. J Urol1998;159: 17-23.
16. Maghsoudi R, AmjadiM, Norizadeh D, Hassanzadeh $\mathrm{H}$. Treatment of ureteral stones: A prospective randomized controlled trial on comparison of Ho:YAG laser and pneumatic lithotripsy. Indian J Urol 2008; 24(3): 352-354.

17. Fong $\mathrm{Y}, \mathrm{Ho}$ Sh, Peh H, Ng F, Lim P, Quek P, et al . Extracorporeal shockwave lithotripsy and intracorporeal lithotripsy for proximal ureteric calculi. Ann Acad Med Singapore 2004;33:80-3.

18. Manohar T, Ganpule A, Desai M. ComparetiveEvaluaton of swiss Lithclast 2 versus Holmium:YAG LASER Lithotripsy for Impacted Upper-Ureteral Stones. J Endourol 2008; 22:443446. 